\title{
Ciência e Natureza nas páginas da Revista da Escola de Engenharia de Porto Alegre (1914- 1930)
}

\author{
Science and Nature in the pages of \\ Journal of the School of Engineering of Porto Alegre (1914-1930)
}

Fabiano Quadros Rückert*

Resumo: Nas primeiras décadas da República a Escola de Engenharia de Porto Alegre foi um importante núcleo de produção e difusão da Ciência no sul do Brasil. A partir de 1914, esta instituição passou a publicar a Revista EGATEA divulgando diferentes tipos de pesquisas e registrando nas suas páginas elementos do discurso científico da sua época. A proposta principal deste artigo consiste em explorar o potencial da Revista EGATEA como fonte documental para o estudo da História Ambiental, articulando $\quad 0 \quad$ binômio Ciência/Natureza. A primeira parte do artigo aborda as relações entre a Escola de Engenharia de Porto Alegre e o governo do Partido Republicano RioGrandense e oferece subsídios para compreensão do perfil editorial da EGATEA; a segunda destaca questões referentes ao uso da Ciência para exploração da Natureza; e a terceira
Abstract: In the first decades of the Republic School of Engineering of Porto Alegre was an important center for the production and dissemination of science in southern Brazil. From 1914, this institution has been publishing the magazine EGATEA disclosing different types of research and recording on their pages elements of scientific discourse of his time. The main purpose of this article is to explore the potential of EGATEA Magazine as documentary source for the study of environmental history, articulating the binomial Science/Nature. The first part of the article deals with the relationship between the School of Engineering of Porto Alegre and the government of Rio-grandense Republican Party and offers subsidies for understanding the publishing profile EGATEA; the second highlights issues related to the use of science to nature exploration; and the third part includes issues about the process of

\footnotetext{
* Doutorando em História pelo PPGH da UNISINOS. Bolsista CAPES - PROSUP. Membro do GT de História Ambiental da ANPUH-RS. Professor da Rede Municipal de São Leopoldo RS.
} 
parte contempla matérias sobre o processo de modernização das atividades agrárias no Rio Grande do Sul da Primeira República.

Palavras-chave: Ciência, Natureza, EGATEA, Primeira República. modernization of agricultural activities in Rio Grande do Sul the First Republic. Keywords: Science, Nature, EGATEA, First Repubic.

\section{I: A Revista EGATEA como produto da Escola de Engenharia de Porto Alegre}

A história da Escola de Engenharia de Porto Alegre tem recebido a atenção de diversos historiadores que a partir de diferentes abordagens, destacam temas como as relações desta instituição com o Partido Republicano Rio-Grandense ${ }^{1}$, a influência do positivismo na sua organização $^{2}$ e o interesse da comunidade germânica do Rio Grande do Sul pelo ensino da Engenharia ${ }^{3}$. Criada por um grupo de engenheiros residentes em Porto Alegre, a Escola de Engenharia iniciou suas atividades em 1897 incorporando elementos do modelo alemão e do modelo norte-americano de ensino politécnico.

A proposta de ensino adotada pelos criadores da Escola de Engenharia de Porto Alegre encontrou receptividade do governo estadual que passou a apoiar financeiramente os trabalhos da instituição. Contando com recursos públicos expressivos, sobretudo depois de $1908^{4}$, a Escola

\footnotetext{
${ }^{1}$ HEINZ, Flávio. Positivistas e Republicanos: os professores da Escola de Engenharia de Porto Alegre entre a atividade política e a administração pública (1896-1930). Revista Brasileira de História. Repúblicas, São Paulo: ANPUH, v. 29, n. 58 p. 263-391, jul./dez. 2009.

2 PEZAT, Paulo Ricardo. Juvenal Miller e a difusão do positivismo nos primórdios da República. In: ALVES, Francisco das Neves (Org.). Por uma história multidisciplinar do Rio Grande. Rio Grande: FURG, 1999. p. 187-194.

${ }^{3}$ GERTZ, René. O aviador e o carroceiro: política, etnia e religião no Rio Grande do Sul dos anos 20. Porto Alegre: EDIPUCRS, 2002.

${ }^{4}$ Em 1908 a Escola de Engenharia passou a receber 2\% da "taxa profissional" arrecadada anualmente pelo governo estadual. Em 1909 a Assembleia Estadual ampliou essa contribuição para 4\% da taxa, contribuindo diretamente para a ampliação dos cursos oferecidos pela instituição (HEINZ, op. cit., p. 269).
} 
manteve a prática de cobrar pelo ensino que oferecia - abrindo exceção para os alunos pobres do Instituto Técnico Profissional, chamado a partir de 1917, de Instituto Parobé5.

A criação da Revista EGATEA,ocorrida em 1914, foi parte do processo de expansão das atividades da Escola de Engenharia de Porto Alegre. Esta expansão se processava no plano interno e externo da instituição: no plano interno ela ampliava o número de instituições sob a sua administração, oferecia novos cursos e ampliava o número de alunos ${ }^{6}$; no plano externo, ela reforçava suas relações com a cúpula do Partido Republicano Rio-Grandense (formando profissionais para os quadros técnicos do governo estadual) e buscava difundir assuntos de interesse científico para um público mais amplo através da EGATEA. Na primeira edição da revista, encontramos um esboço das suas intenções.

EGATEA é um nome symbólico que synthetiza essa federação de institutos constituintes da Escola de Engenharia de Porto Alegre. Não se infira que esta publicação se destine a ser uma revista de caracter puramente polytechnico, envolta na rigidez híspida das formulas mathematicas, acessível apenas a um limitado número de profissionaes, hieroglyphica para o público em geral.

A Escola de Engenharia de Porto Alegre, orientada segundo directrizes sociais modernas, nunca se limitou a ser apenas um estabelecimento de instrucção polytechnica. Creada para o progresso do Rio Grande, dele será um factor e a todas as questões que o interessam, directa ou indirectamente se vinculará.

\footnotetext{
5 Sobre a história do ensino técnico-profissional no Rio Grande do Sul na Primeira República, recomenda-se o estudo da Dissertação de Raquel Rodrigues de Lima, intitulada As Escolas de Artes e Ofícios do Rio Grande do Sul: 1900-1930. Porto Alegre: UFRGS, 1997.

${ }^{6}$ A Escola de Engenharia de Porto Alegre foi gradualmente ampliando a sua rede de alunos através da criação de novas escolas voltadas para o ensino técnico e profissionalizante. Seguindo as diretrizes do PRR que considerava a educação técnica como condição para o "progresso", a Escola de Engenharia passou a administrar o Instituto de Agronomia e Veterinária, o Instituto de Zootecnia, o Instituto Experimental de Agricultura, a Escola Industrial Elementar, o Instituto de Química Industrial e um conjunto Estações Experimentais de Agricultura espalhado em diferentes regiões do Estado. (HEINZ, op. cit., p. 269)
} 
A revista que ela agora atira a publicidade, destinada a ampliar sua esphera de acção, não poderia fugir ao pensamento vivificador que anima a instituição e será, pois, em ultima analyse, um orgam dos interesses geraes do Rio Grande do $\mathrm{Sul}^{7}$.

Seguindo as diretrizes de escrever sobre os "interesses geraes" do Rio Grande do Sul, sem abrir mão dos seus compromissos com o ensino politécnico, a revista EGATEA passou a publicar artigos de diferentes áreas científicas, dentre as quais podemos destacar a Zootecnia, a Botânica, a Geologia, a Engenharia Sanitária, a Agronomia e a Veterinária. A revista publicava textos de membros do seu grupo docente, traduzia artigos do exterior e também publicava textos de profissionais técnicos que não pertenciam ao seu quadro docente. Resultados parciais de pesquisas e notícias tecnológicas também recebiam espaço nas páginas da EGATEA. Informações da instituição (número de alunos, eventos, cursos, direção, etc.), dados climáticos e estudos sobre a fauna, a flora e o solo do Rio Grande do Sul completavam o quadro geral da revista.

O conjunto de textos publicados na EGATEA no período de 1914 a 1930, apesar da diversidade de temas e das particularidades de cada área científica, apresentava dois aspectos em comun: (1) o objetivo de difundir o saber técnico e (2) a valorização das ações do poder púbico voltadas para o "progresso" do Rio Grande do Sul ${ }^{8}$. E neste conjunto de textos, encontramos uma complexa rede de interações entre a Ciência e a Natureza.

\section{II: Ciência e exploração da Natureza na EGATEA}

Antes de avançarmos neste ponto do artigo, é necessário expor algumas considerações a respeito das interações entre a Ciência e Natureza. Em

\footnotetext{
${ }^{7}$ Editorial. EGATEA. Volume I, n. 1, 1914, p. 1.

8 A valorização das ações do poder público nas páginas da EGATEA pode ser considerada uma extensão dos vínculos entre a Escola de Engenharia de Porto Alegre e o Partido Republicano Rio-Grandense. Segundo Flávio Heinz: "O vínculo da Escola de Engenharia com o estado se materializava em três níveis: na identidade comum assegurada pelo positivismo e pelo vínculo com o PRR; pela percepção estratégica da Escola "como agente de fomento do desenvolvimento econômico e tecnológico" no estado e, finalmente, pela ajuda financeira pública à Escola." (HEINZ, op. cit., p. 269)
} 
primeiro lugar, devemos ter em conta, que o conceito de natureza foi cientificamente construído com base na distinção entre o ser humano e os outros elementos existentes no planeta ${ }^{9}$. Esta distinção, amparada pelo racionalismo cartesiano, potencializou a crença na capacidade humana de compreender os fenômenos da Natureza e de aprimorar o uso dos recursos naturais. Isto significa dizer que a ciência forneceu os "códigos" para a interpretação do mundo natural e, ao mesmo tempo, produziu técnicas para intermediar as relações entre os humanos e o ambiente.

$\mathrm{Na}$ fonte documental destacada neste artigo, encontramos concepções de Natureza construídas pela Ciência do começo do século XX; naquele contexto, as relações entre o ser humano e o ambiente natural estavam permeadas por uma ideologia de "dominação" e de "humanização" do mundo natural - uma ideologia que apesar de enfraquecida ao longo das ultimas décadas, ainda permanece influenciando nosso comportamento. Referindo-se ao uso da Ciência na "humanização da natureza", Bernard Charlot e Veleida Anahi afirmam que:

Essa tentativa pode tomar distintas formas - do século XVII até os dias de hoje -, mas sempre sustentada pela ideia de Progresso. A natureza não é mais uma potência benfeitora ou, ao contrário, perigosa, que rege o destino do homem, mas uma grande mecânica - nos séculos XVII e XVIII - da qual o homem pode conhecer suas leis, escritas em uma linguagem matemática e da qual pode se tornar mestre e possuidor. Assim, torna-se possível ideia de uma natureza externa ao homem - a matéria de um lado, o espírito de outro, como em Descarte - e a de uma luta entre a natureza e o homem ${ }^{10}$.

Diversos autores concordam que a racionalidade científica, baseada na distinção entre o ser humano e os demais elementos do mundo natural, comprometeu a compreensão das nossas relações com o meio ambiente ${ }^{11}$.

\footnotetext{
9 THOMAS, Keith. O homem e o meio ambiente. Mudanças de atitude em relação às plantas e aos animais (1500-1800). São Paulo: Companhia das Letras, 1989.

10 CHARLOT, Bernard; SILVA, Veleida Anahi da. Relação com a natureza e educação ambiental. In: SATO, Michelé; CARVALHO, Isabel C. Moura (Orgs.). Educação Ambiental. Pesquisa e Desafios. Porto Alegre: ARTMED, 2006. p. 65-77.

11 A crítica ao modelo científico de relação entre o ser humano e a natureza tem sido construída por diversos intelectuais contemporâneos, dentre os quais, cabe destacar Fritjof
} 
Reconhecer os efeitos colaterais da racionalidade científica sem desistir do potencial da Ciência para conter a degradação ambiental tem sido um grande desafio para o mundo contemporâneo. A superação deste desafio implica na aceitação de que o saber científico é incompleto, imperfeito e permeado de dúvidas que comprometem a sua credibilidade social.

Para a geração nascida nas décadas finais do século XX, a Ciência não está isenta de críticas e desconfianças. Mas a postura de desconfiança diante da Ciência não existia em 1914 quando a Escola de Engenharia de Porto Alegre publicou o primeiro número da Revista EGATEA. O estudo dos textos da revista indica que os editores e autores expressavam otimismo em relação à capacidade humana de controlar a natureza pelo saber científico. Este controle seria obtido mediante a compreensão dos fenômenos naturais e o aperfeiçoamento das técnicas. Em linhas gerais, esse era o contexto científico da época e, sendo uma revista de ensino politécnico, a EGATEA estava comprometida com a difusão do saber científico e com a modernização do Rio Grande do Sul.

No artigo intitulado $A$ exploração das madeiras, publicado em 1915, a revista crítica os métodos e instrumentos de derrubada de árvores usados pelos "matteiros" no Brasil apontando problemas como o desperdício de partes do tronco e a falta de controle sobre a direção da queda da árvore que acarretava a perda de "outras tantas que lhe poderiam ser uteis mais tarde". Faltava ao Brasil o conhecimento e o uso de técnicas estrangeiras mais eficientes no aproveitamento da madeira. Mas a questão não era simplesmente mudar as técnicas de abatimento ou abandonar a prática das queimadas. Era preciso também mobilizar esforços em prol da valorização das árvores - valorização aqui entendida no sentido financeiro da palavra.

As mattas que representam a defesa e a fecundidade das terras, a salubridade e a riqueza de grandes zonas do globo, encontram em muitos paizes a justa protecção que merecem. Reunem-se os congressos,

Capra com o livro O Ponto de Mutação: A Ciência, a Sociedade e a Cultura Emergente. São Paulo: Cultrix, 1982; Bruno Latour, autor do livro Jamais fomos modernos: ensaios de antropologia simétrica. Rio de Janeiro: Editora 34, 1994. Na área das Ciências Humanas, os sociólogos Enrique Leff, Juan Martinez Alier e Héctor Alimonda são referências para a construção desta crítica. 
onde todas as classes de indivíduos desde o scientista até o simples operário, todos concorrem para a realização verdadeira da defeza das mattas. [...]

Nós, entretanto, ainda não nos interessamos com ardor por esta questão que tanta influência pode exercer na nossa vida econômica ${ }^{12}$.

Em linhas gerais, o artigo sugere que explorar as "mattas" com mais eficiência e "cultivar futuras florestas que substituam constantemente a madeira que a indústria e o comércio pouco a pouco consomem", seriam formas de proteger a natureza do Brasil ${ }^{13}$. Mas entre o que a EGATEA estava divulgando em seus textos sobre o extrativismo da madeira e o que estava em curso no Rio Grande do Sul da Primeira República havia uma grande diferença. $\mathrm{Na}$ parte norte do estado, a "indústria da madeira" avançou de forma predatória sobre a Floresta Subtropical e provocou profundas mudanças na paisagem da região ${ }^{14}$.

O interesse da EGATEA pelas técnicas estrangeiras de exploração de recursos naturais está registrado em diversos textos da revista. No caso específico da extração da madeira, a participação do governo dos Estados Unidos na promoção e controle do corte foi abordada no artigo Organização do Serviço Florestal dos Estados Unidos, publicado em 1921 ${ }^{15}$. O artigo explica o sistema norte-americano de divisão das áreas florestais em distritos submetidos aos cuidados do governo federal. $\mathrm{O}$ extrativismo de madeira era uma das áreas de atuação do Forest Service que também atuava na concessão de áreas para cultivo e pastagem dentro das reservas nacionais, fiscalizava a caça, combatia incêndios e realizava trabalhos de manutenção das estradas e das instalações usadas pelos seus funcionários. A presença de profissionais com formação superior nos cargos mais importantes do Forest

${ }^{12}$ BARBEDO, S. A exploração das madeiras. EGATEA. Volume I, n. 5, 1915, p. 221.

13 É pertinente dizer que apesar de ser antigo, este discurso de exploração eficiente dos recursos naturais ainda desfruta de muitos adeptos no Brasil e no exterior.

${ }^{14} \mathrm{O}$ livro de Liliane Irma Mattje Wentz, intitulado: Os caminhos da madeira: região norte do Rio Grande do Sul (1902-1950). Passo Fundo: Editora UPF, 2004 apresenta um panorama geral do desenvolvimento da "indústria da madeira" no estado. Para os interessados no processo de desmatamento ocorrido no Estado, recomenda-se também a obra Terra de Promissão: uma introdução à Eco-história da colonização no Rio Grande do Sul. Passo Fundo/Santa Cruz do Sul: EDUPF/EDUNISC, 2006, escrita pelos historiadores Juliana Bublitz e Marcos Sílvio Corrêa.

15 MELLO, Sezefredo S. de. Organização do Serviço Florestal dos Estados Unidos. EGATEA. Volume VI, n. 6, 1921, p. 338-346. 
Service recebeu elogios do autor do texto que expressou admiração pelos estudos com madeiras realizados no "Laboratório de Productos Florestaes" norte-americano.

O Laboratório de Productos Florestaes, como é evidente, tem estimulado e favorecido grandemente o desenvolvimento da indústria de madeira e o das suas derivadas, tendo, portanto, concorrido em não pequena escala para o progresso do paiz. Em várias experiências levadas a effeito no Laboratório, verificou-se e provouse que muitas madeiras anteriormente consideradas como infferiores têm attributos que as collocam em igual plano de importância e utilidade as melhores espécies locais conhecidas. [...]. Experiências relativas à preservação da madeira têm mostrado a conveniência do tratamento de muitas espécies, especialmente coníferas, por meio do uso do creosoto, chloreto de zinco poucos outros preservativos, que são aplicados de vários modos. Madeiras, tratadas com o creosoto, por exemplo, têm alcançado um coefficiente de duração superior de 50 a $100 \%$, e mesmo mais aos das mesmas que não foram tratadas ${ }^{16}$.

O modelo norte-americano de uso das áreas florestais que foi elogiado pela revista EGATEA nos anos 20, certamente seria reprovado pelos ambientalistas contemporâneos, mas na época, as relações entre a Ciência e a Natureza visavam, sobretudo, atender interesses econômicos. Era necessário conhecer mais sobre os recursos naturais para evitar desperdícios, ampliar as opções de extração, prolongar a durabilidade da madeira, replantar para garantir a continuidade do extrativismo e, acima de tudo, maximizar os lucros. Dentro deste contexto marcado por interesses econômicos, as matérias publicadas na revista indicam o surgimento de uma preocupação científica com o uso racional dos recursos naturais. A preocupação de fato existia e, mesmo estando submetida a uma lógica capitalista, a Ciência estava aos poucos contribuindo para a crítica a depredação dos recursos naturais.

${ }^{16}$ Ibidem, p. 342. 
No começo do século XX, a Ciência ainda acreditava no seu potencial de controlar a Natureza e que ao mesmo tempo ensaiava teorias e métodos para avaliar a nocividade das ações humanas. $\mathrm{O}$ artigo intitulado Sobre o concurso das árvores para trasfegar água da atmosfera é um interessante exemplo do pensamento científico da época ${ }^{17}$. Originalmente apresentado na Academia de Sciencias de Paris, em dezembro de 1919, e publicado pela EGATEA em 1922, ele apresenta resultados de estudos sobre a retenção de líquidos em árvores e articula este fenômeno natural com o aproveitamento econômico da "hulha branca." Com base em dados científicos, o autor do artigo defendeu a necessidade de conservação das árvores em áreas montanhosas e expôs as vantagens econômicas que se poderia obter dela.

A maior parte das bacias montanhosas cujas águas são utilizadas como hulha branca, achando-se infelizmente desflorestadas ou pouco arborizadas, essa indústria encontra para a sua installação condições desfavoráveis. Tratando-se de montanhas sufficiente arborizadas, com a mesma despesa, poder-se-ia captar águas mais abundantes, pôr em acção forças motoras muito mais consideráveis, e obter-se o kilowatt por um preço de custo menos elevado.

É preciso, pois, quanto antes, reflorestar as montanhas para augmentar os mananciais de hulha branca. A Administração das Águas e Florestas resolveu todas as dificuldades technicas laboriosas desta operação, para cuja realização o Parlamento trouxe sua contribuição votando leis especiais e a de 2 de Julho de 1913 "tende a favorecer o reflorestamento" 18 .

A citação destacada deve ser pensada como um fragmento histórico do discurso científico construído no começo do século XX e, nesta condição, ela oferece algumas possibilidades de interpretação do passado. A procedência do texto sinaliza para o envolvimento da EGATEA com o um processo de internacionalização dos saberes científicos. Outro aspecto que podemos observar na citação, é a relação entre a preservação das árvores

17 DESCOMBES, Paul. Sobre o concurso das árvores para trasfegar água da atmosfera. EGATEA. Volume VII, 1922, p. 143-145.

${ }^{18}$ Ibidem, p. 145. 
nas montanhas com possibilidade de ampliação de lucros na geração de energia.

O texto As árvores de Porto Alegre, datado de 1920, é uma exceção no conjunto de matérias referente ao uso das árvores publicadas na EGATEA, nele, não encontramos um benefício financeiro como motivo para a valorização das árvores da cidade. Trata-se de um texto escrito com tons de nostalgia e com uma ponderada crítica a preferência por árvores exóticas em detrimento das nativas e mais antigas.

Não fossemos nós um povo novo, iconoclasta; tivéssemos o culto da tradição; fossemos capazes de sentir a belleza do que é nativo, do que é nosso, e a alameda conservada, protegida, melhorada, nós a passaríamos para a geração de amanhã como a recebemos da geração de hontem [...]

Há quem diga que Porto Alegre não tem bellas árvores. Não as tem para quem não sabe ver ${ }^{19}$.

A preocupação com a arborização de Porto Alegre não deve ser dissociada do contexto de expansão urbana que a capital do Rio Grande do Sul estava vivendo nas primeiras décadas do século $\mathrm{XX}$, naquele contexto, a derrubada de árvores seculares para a abertura de ruas não passou despercebida pelas páginas da EGATEA.

Em diversas matérias, a revista destacou questões referentes à organização do espaço urbano e a manutenção da higiene e insistiu na necessidade de uso das tecnologias procedentes do exterior. $\mathrm{O}$ interesse pela urbanização motivou a publicação de textos sobre técnicas de depuração do lixo estudadas Europa ${ }^{20}$; tendências do urbanismo no "arruamento das cidades" 21 ; além de projetos e obras de saneamento nas cidades de Porto Alegre $^{22}$ e em Rio Grande ${ }^{23}$. Neste conjunto de temas relacionados ao

${ }^{19}$ COARACY, Vivaldi. Árvores de Porto Alegre. EGATEA. Volume V, n. 4, 1920, p. 230231.

${ }^{20}$ A depuração do lixo e dos resíduos urbanos. EGATEA. Volume X, n. 2, 1925, p. 453 457. A depuração do lixo e dos resíduos urbanos. EGATEA. Volume XI, 1926, p. 32-42.

${ }^{21}$ HOFMANN, B. Notas sobre o arruamento das cidades. EGATEA. Volume X, n. 1, 1925 , p. 1-7. - HOFMANN, B. Notas sobre o arruamento das cidades. EGATEA. Volume X, n. 2, 1925, p. 79-83.

${ }^{22}$ MACIEL, João Moreira. Melhoramentos de Porto Alegre. EGATEA. Volume I, n. 3, 1914 , p. $124-128$. 
ambiente urbano - aqui entendido como parte da Natureza - encontramos diversos argumentos em favor da aplicação da Ciência na promoção da salubridade urbana.

Analisando o crescimento das cidades no Brasil, o engenheiro Hofmann registrou sua percepção do problema da abertura de novas ruas sem critérios técnicos nos seguintes termos:

Sem obedecer a qualquer methodo previamente assentado, vão sendo abertas as ruas em linhas absolutamente rectas e perpendiculares umas ás outras, conforme o exigirem as conveniências do momento, com desprezo quase absoluto das condições topographicas do terreno, sem obedecer a quaesquer considerações higyenicas (água e esgoto) e attendendo, a maior parte das vezes, as conveniências econômicas dos proprietários dos terrenos arruados. [...]

Si não quisermos comprometer o futuro das nossas cidades, não só quanto ao seu embelezamento como também quanto à salubridade, si quisermo-nos ufanar de possuí-las munidos dos requisitos de uma cidade moderna, construída segundo preceitos modernos, forçoso será abandonar este systema errôneo e adotar outro, o único verdadeiro, que, dictado pela evolução progressista, satisfaz, ao par das necessidades para fácil e desembaraçada circulação de veículos, as exigências sanitárias, de conforto e estética da população ${ }^{24}$.

Hofmann expressou sua admiração pelo trabalho do engenheiro Francisco Rodrigues Saturnino de Brito, considerado uma autoridade internacional na questão do traçado das ruas, mas lamentou que as Escolas de Engenharia do Brasil apresentassem defasagem no estudo deste tema. Assim como diversos autores que publicaram textos na EGATEA, Hofmann acreditava que o Brasil carecia da aplicação dos preceitos científicos que existiam na Europa e/ou nos Estados Unidos, exemplos da sua comprovada

${ }^{23}$ A revista dividiu os estudos de Francisco Rodrigues Saturnino de Brito para o saneamento da cidade do Rio Grande em partes publicadas nas seguintes edições: Volume IV, 1918, p. 75-84. - Volume IV, n. 4, 1918, p. 167-185. - Volume IV, n. 5, 1918, p. 220-242. - Volume IV, n. 6, 1919, p. 283-308.

${ }^{24}$ HOFMANN, B. Notas sobre o arruamento das cidades. EGATEA. Volume X, n. 1, 1925, p. 2. 
eficiência. Não nos cabe aqui discutir o peso da influência externa no pensamento científico brasileiro, porém, não podemos desconsiderar a importância dessa influência nas relações entre a Ciência e a Natureza que estavam em curso no Rio Grande do Sul da Primeira República.

$\mathrm{O}$ destino do lixo e o abastecimento de água nas cidades também receberam expressiva atenção da Revista EGATEA. Era necessário pensar práticas eficientes de recolhimento e armazenamento da crescente produção de lixo nas cidades e ampliar a oferta de água potável e, para ambos os casos, a Europa e os Estados Unidos ofereciam exemplos pioneiros. Contrapondo-se aos exemplos do exterior, as cidades brasileiras apresentavam problemas na gestão do lixo.

De summa importância é a qualidade do recipiente em que deve ser recolhido o lixo pelos moradores. São Paulo (que é uma das grandes capitaes do Brasil) se vê, é uma lastima: latas descobertas, caixões imprestáveis, tudo serve para colecta de resíduos. O resultado é o que por ahi se verifica: os cães vadios saqueiam esse vasilhame disparatado e espalham pelas ruas as imundices, empestando o ar e poluindo o solo.

Em Manaus e no Pará, climas mais quentes e onde portanto, a putrefação é mais rápida, assistimos scenas como as que se observam em São Paulo ${ }^{25}$.

O jogo de comparações entre as cidades brasileiras e as cidades europeias e norte-americanas era mediado pela Ciência que corretamente aplicada aos elementos naturais (topografia, clima, vegetação, hidrografia, etc.) poderia melhorar as condições de salubridade do ambiente urbano.

A recorrência das questões urbanas na revista EGATEA indica um crescente interesse dos seus colaboradores pela aplicação da Ciência em benefício das cidades. Mas o foco principal da revista estava nas questões rurais e, mais especificamente, nas técnicas de cultivo e nos procedimentos para criação de animais que estavam sendo discutidas e experimentadas pela comunidade científica da época. Neste sentido, a EGATEA estava em sintonia com o modelo econômico do Rio Grande do Sul na Primeira

${ }^{25}$ ELEJADE, Benito. Saneamento das Cidades. O lixo: $2^{\mathrm{a}}$ parte. EGATEA. Volume II, n. 2, 1915, p. 67. 
República e reconhecia a importância das atividades agrárias para o desenvolvimento econômico do Estado ${ }^{26}$.

\section{III: A revista $E G A T E A$ e modernização agrária no Rio Grande do Sul}

No mundo rural do Rio Grande do Sul da Primeira República, as relações entre a Ciência e a Natureza seguiam uma lógica de aumento na produção e de ampliação do controle sobre as variáveis ambientais. Mas essa lógica nem sempre estava explícita, em alguns casos, as novas técnicas eram apresentadas como resultado de experiências que buscavam aprimorar o conhecimento existente ou solucionar determinados problemas. O saber científico, apesar de valorizado nas suas contribuições para o progresso humano, aparecia então permeado de dúvidas e imperfeições. E para qualificá-lo, a compreensão científica dos fenômenos naturais era um objetivo que deveria ser alcançado e, sobretudo, aplicado nas atividades agrárias.

Um exemplo interessante de como a EGATEA incentivava o uso do saber científico para aumentar a produtividade agrária pode ser encontrada nas matérias referentes à suinocultura ${ }^{27}$. $\mathrm{O}$ autor do texto $A$ suinocultura riograndense considerava necessário o melhoramento genético dos rebanhos existentes e considerava o porco "crioulo" - tipo predominante nas áreas de colonização alemã e italiana - como um animal que apresentava dificuldades na engorda. $\mathrm{O}$ autor também recomendava melhoramentos nas práticas de alimentação dos suínos.

\footnotetext{
26 A bibliografia sobre o desenvolvimento econômico do Rio Grande do Sul na Primeira República é extensa. Nos anos 80, surgiram importantes estudos publicados pela Editora Mercado Aberto, na Série Documenta, dentre os quais podemos destacar RS: agropecuária colonial \& industrialização (PESAVENTO, 1983); RS: economia \& conflitos políticos na República Velha (FONSECA, 1983); Modernização e crise na agricultura (TAMBARA, 1983). No conjunto de estudos mais recentes, importa citar a Tese de Ronaldo Herrlein Jr., Rio Grande do Sul, 1889-1930: um outro capitalismo no Brasil Meridional? Campinas: UNICAMP, 2000, e a Tese de Gunter Axt, publicada com o título Gênese do Estado Moderno no Rio Grande do Sul, 1889-1929. Porto Alegre: Editora Paiol, 2011.

${ }^{27} \mathrm{O}$ desenvolvimento da suinocultura no Rio Grande do Sul foi abordado por Sandra Jatahy Pesavento (1983) na obra RS: Agropecuária colonial \& industrialização. Segundo Pesavento, a suinocultura possibilitou o surgimento da "indústria da banha" e a exportação deste produto tornou-se uma importante fonte de renda para o Rio Grande do Sul, sobretudo para as áreas de colonização alemã e italiana. A autora também explorou os conflitos que surgiram entre os pequenos produtores rurais criadores de porcos, os empresários do beneficiamento da banha e os comerciantes que acumulavam expressivos lucros com a exportação deste produto.
} 
Com a introdução de boas raças e com melhoramentos na alimentação, o criador conseguirá vender seus capados na metade do tempo em que costuma entregar os crioulos de hoje, com muito maior peso, com sensível diminuição de capital empatado, e, com risco de infecções e de outras causas contrárias diminuídas à metade do tempo ${ }^{28}$.

A qualificação das instalações de criação de porcos é o tema das matérias Combate às lombrigas na suinocultura ${ }^{29}$ e Chiqueiros ou Pocilgas $^{30}$, ambas escritas por Celeste Globato, em 1923 e 1925. Na condição de Engenheiro Agrônomo e de líder político do PRR na região serrana, Celeste Globato também publicou textos na Revista EGATEA sobre a produção de forragens ${ }^{31}$ e sobre viticultura e vinicultura ${ }^{32}$.

A adubação química, apesar de estar em fase de expansão, era vista com certas ressalvas, uma vez que ainda não estavam "perfeitamente reconhecidos os princípios fundamentais que regem a importante prática das adubações" "33. Depois de reconhecer uma tendência de crescimento no uso dos chamados "adubos químicos completos," Ochoa apresentou os resultados das suas experiências com a adubação química e fez uma advertência ao uso excessivo daquele recurso.

Effectivamente, não basta aplicar misturas de ingredientes chimicos, recommendados pelos seus fabricantes, em lotes culturais organizados nas fazendas pelos agentes e revendendores interessados na

\footnotetext{
${ }^{28}$ LAGES, Waldemar Ramos. A suinocultura rio-grandense. EGATEA. Volume VI, n. 4, 1921, p. 182-184.

${ }^{29}$ GLOBATO, Celeste. Combate às lombrigas na suinocultura. EGATEA. Volume VIII, 1923, p. 51-53.

30 GLOBBATO, Celeste; HOOGENSTRAATEN, Chrétien. Chiqueiros ou pocilgas. EGATEA. Volume X, n. 2, 1925, p. 457-464.

${ }^{31}$ GLOBBATO, Celeste. Economia das Forragens. EGATEA. Volume I, n. 2, 1914.

${ }^{32}$ GLOBBATO, Celeste. Notas de viticultura. EGATEA. Volume I, n. 3, 1914, p. 120-124. GLOBBATO, Celeste. No vinhedo. EGATEA. Volume I, n. 5, 1915, p. 174-176. GLOBBATO, Celeste. Uma doença microbiana nos vinhos. EGATEA. Volume II, n. 1, 1915 , p. 4-8.

${ }^{33}$ OCHOA, G. D. O equilibro da fertilidade dos solos. EGATEA. Volume XI, n. 1, 1926, p. $1-14$.
} 
introdução de taes adubos, pois o bom resultado pode ser ilusório e passageiro ${ }^{34}$.

Apesar da sua advertência, Ochoa não assumiu uma oposição declarada ao uso dos adubos químicos comercializados na época. A preocupação deste agrônomo estava nas consequências negativas que os adubos químicos poderiam provocar a médio e longo prazo. $\mathrm{Na}$ sua concepção, mais importante do que recorrer aos adubos químicos, era a adoção de cultivos adaptados para cada tipo de solo, da alternância dos cultivos e as técnicas de adubação orgânica ${ }^{35}$. Hoje, sabemos que as ideias do agrônomo Ochoa faziam parte de um discurso vencido pela força da Revolução Verde, mais ainda sabemos muito pouco sobre os embates travados no âmbito das ciências agrárias.

Se a adubação química era vista com ressalvas, o mesmo não se pode dizer das experiências com novos tipos de cultivos - tema destacado em diversos artigos da EGATEA. A busca de cultivos mais produtivos poderia ser feita com a introdução de novas sementes ${ }^{36}$ ou pelas técnicas de enxerto ${ }^{37}$. Em ambos os casos, as prioridades eram aumentar a resistência do cultivo às pragas e às variações climáticas e aumentar a produtividade.

Notícias de pesquisas de adubação e cultivo feitas por professores e alunos da Escola de Engenharia de Porto Alegre podem ser encontradas em diversas edições da Revista EGATEA. As notícias apresentavam um determinado problema, descreviam os procedimentos adotados e os resultados encontrados. Como exemplo, podemos citar a notícia intitulada Boletim da Estação Experimental - Adubação espalhada ou localizada? O problema abordado foi a variação no aproveitamento do adubo; o procedimento adotado foi a adubação de dois campos de cultivo com a mesma extensão (um com o adubo concentrado em torno das sementes e o outro com o adubo disperso sobre todo o solo arado); os resultados indicaram que a adubação concentrada produziu melhores resultados. $\mathrm{Na}$

\footnotetext{
${ }^{34}$ Ibidem, p. 2

35 OCHOA, G. D. Apontamentos sobre a determinação de phosphato no solo. EGATEA. p. 160-162. - OCHOA, G. D. Necessidade do estudo shystemático do solo. EGATEA. Volume XI, p. 250-256.

${ }^{36}$ FERTSCH, E. Melhoramento de espécies de cereais (especialmente do trigo). EGATEA. Volume VII, 1922, p. 146-149.

${ }^{37}$ SCHENK, Emilio. Novos métodos na Pomicultura. EGATEA. Volume V, n. 1, junho de 1919 , p. 43-44
} 
finalização da notícia, o autor recomendou aos agricultores o uso do procedimento de adubação mais produtivo ${ }^{38}$.

Modernizar a produção agrária era o objetivo de diversos estudos feitos pelo grupo discente e pelos professores da EGATEA. E pelo conteúdo dos textos consultados, sabemos que a modernização também era pensada a partir de experiências do exterior. Geralmente, as experiências eram positivas, mas no texto Conservae os passarinhos ${ }^{39}$, publicado em 1915, encontramos uma situação diferente: o texto crítica o consumo de passarinhos ocorrido na Itália e adverte para os riscos da difusão deste hábito culinário no Brasil. Na opinião do autor, conservar os passarinhos era uma forma eficiente de combater os insetos que comprometem as colheitas e, consequentemente, era uma prática que deveria ser incentivada pelo governo e pela sociedade.

\section{Considerações finais}

Diante do que foi proposto na introdução do artigo, procurei explorar o potencial da Revista EGATEA como fonte documental para o estudo da História Ambiental, articulando o binômio Ciência/Natureza no contexto do Rio Grande do Sul da Primeira República. No desenvolvimento da proposta, três aspectos ganharam relevância: (1) o interesse da EGATEA pela aplicação da Ciência no uso dos recursos naturais; (2) uma incipiente preocupação com os efeitos colaterais das intervenções humanas no meio ambiente; (3) a busca pela modernização das atividades agrárias no Rio Grande do Sul. Cada um dos três aspectos destacados sinaliza a possibilidade de novas pesquisas e não há necessidade de pensá-los de forma fragmentada, uma vez que todos estavam permeados de um discurso científico e influenciados pelos vínculos da Escola de Engenharia de Porto Alegre com o governo estadual.

E para finalizar este artigo, importa ressaltar que o ideal de exploração da Natureza através da Ciência, encontrado em diversos textos da EGATEA, foi em algumas ocasiões, acompanhado de uma reflexão crítica sobre as teorias e métodos oferecidos pelo saber científico. Isto

38 GLOBATO, Celeste. Boletim da Estação Experimental - Adubação espalhada ou localizada? EGATEA. Volume IV, n. 1, 1917, p. 29-32.

${ }^{39}$ GHESCH, Rudolf. Conservae os passarinhos. EGATEA. Volume I, n. 5, 1915, p. 233234. 


\section{Fabiano Quadros Rückert}

significa dizer que a Ciência registrada nas páginas da fonte documental pesquisada, não estava indiferente aos efeitos negativos das suas intervenções na Natureza. 